\title{
CHARACTERISATION OF Ru/C CATALYSTS FOR AMMONIA SYNTHESIS BY OXYGEN CHEMISORPTION
}

\author{
Ilenia Rossetti ${ }^{a}$, Nicola Pernicone ${ }^{b}$ and Lucio Forni ${ }^{a^{*}}$ \\ a Dipartimento di Chimica Fisica ed Elettrochimica, Università di Milano, \\ via Golgi, 19 I-20133 Milano, Italy, b Via Pansa, 7 Novara, Italy
}

\begin{abstract}
A standard chemisorption procedure has been set up for the determination of $\mathrm{Ru}$ dispersion in $\mathrm{Ru} / \mathrm{C}$ catalysts. Pulse chemisorption of oxygen was carried out at $0^{\circ} \mathrm{C}$, after having proved that no corrosive chemisorption phenomena are present. An average chemisorption stoichiometry $R u^{*} / O=1.0$ was experimentally determined through measurements on Ru black. The procedure was applied to the investigation of promoted and unpromoted Ru/C catalysts for ammonia synthesis, supported on two different carbon supports. The main factor influencing Ru dispersion showed to be Ru loading, while the addition of even large amounts of Ba-Cs-K promoters has practically no influence. It is also briefly discussed how such results can help in elucidating several aspects of the behaviour of $\mathrm{Ru} / \mathrm{C}$ as catalyst for ammonia synthesis.
\end{abstract}

Keywords: $\mathrm{O}_{2}$ chemisorption, $\mathrm{Ru} / \mathrm{C}$ catalyst, ammonia synthesis, Ru metal dispersion.

*) Corresponding author. Fax: +39-02-50314300, e-mail: lucio.forni@unimi.it 


\section{INTRODUCTION}

In the recent past, promoted $\mathrm{Ru} / \mathrm{C}$ catalyst has been proposed as substitute for the traditional Fe-based one for ammonia synthesis. Indeed, it showed more active under milder reaction conditions [1-5]. In the main patents and applicative papers, a high $\mathrm{Ru}$ content ( $\geq 9$ wt\%) has been usually reported. Furthermore, a structure sensitivity of ammonia synthesis on Ru-based catalysts was hypothesised by Tennison [6] and supported by the reported dependence of the turn-over frequency (TOF) on metal particle size $[7,8]$. However, the evaluation of exposed surface metal atoms, on which the calculation of TOF is based, and of metal particle size, both of them obtained by chemisorption methods, on the basis of assumed values for the average chemisorption stoichiometry, is open to many doubts. As a consequence, it is highly desirable to reevaluate and optimise the procedure for the determination of Ru dispersion, Ru surface area and Ru particle size. Anyone of such physical properties can be determined through chemisorption of a proper probe molecule, provided that the average chemisorption stoichiometry has been experimentally determined. On the other hand, an absolute measurement of the average metal particle size can be performed by other physical techniques, such as XRD (WAXS, SAXS) and TEM, thus allowing a further, and often more reliable, determination of the average chemisorption stoichiometry.

The most commonly suggested probe molecules for characterising supported $\mathrm{Ru}$ are $\mathrm{H}_{2}, \mathrm{O}_{2}, \mathrm{CO}$ and $\mathrm{N}_{2} \mathrm{O}$, but, unfortunately, all of them show some drawbacks, in particular when this metal is supported on active carbon. For instance, $\mathrm{H}_{2}$ chemisorption rate is too low at room temperature, while at higher temperature a spillover phenomenon can take place $[9,10]$. In addition, the formation of subsurface hydrogen species has been reported [11]. CO gives strongly corrosive chemisorption [12], thus precluding any possibility of using it as probe molecule.

Oxygen chemisorption for the measurement of Ru dispersion was firstly proposed 
by Buyanova et. al. about 30 years ago [13]. They used the pulse method at room temperature. The chemisorption stoichiometry $\mathrm{O} / \mathrm{Ru}$ was obtained through calibration with $\mathrm{Ru}$ black and found to be 1.1. A correction was introduced to take into account oxygen adsorption on carbon supports. However, no investigation was done on the effect of chemisorption temperature $\left(25^{\circ} \mathrm{C}\right.$ may not be the best choice). Moreover, Ru particle size determined by TEM did not agree with chemisorption measurements. In another paper [14] frontal chromatography was used and the effect of chemisorption temperature was investigated (plateau between $0^{\circ} \mathrm{C}$ and $60^{\circ} \mathrm{C}$ ), but no reliable chemisorption stoichiometry was reported. More recently [15] a hardly reliable double isotherm method at $-78^{\circ} \mathrm{C}$ was used, without any determination of chemisorption stoichiometry. A pulse oxygen chemisorption method at $0^{\circ} \mathrm{C}$ has been used by Kowalczyk et al. [8], but no detailed study has been reported to prove its validity. However, the use of hydrogen was strongly discouraged. The use of $\mathrm{N}_{2} \mathrm{O}$ decomposition in place of oxygen chemisorption has been proposed too [16], on the basis of what previously done for $\mathrm{Cu}$. The chemisorption stoichiometry $\mathrm{O} / \mathrm{Ru}=$ 0.6-0.7 was obtained through calibration with Ru black. However, no plateau was found when varying the chemisorption temperature and formation of subsurface oxygen was clearly evidenced at the adopted temperature of $130^{\circ} \mathrm{C}$.

Hence, it seems reasonable to conclude that oxygen as probe molecule is the most favourable choice when chemisorption methods are to be used for measuring metal dispersion in supported Ru catalysts.

A complementary approach can be based on the use of physical techniques, such as X-ray Powder Diffraction (XRPD), Small Angle X-rays Scattering (SAXS) and Transmission Electron Microscopy (TEM) for the measurement of the average metal particle size. From these data and from the chemisorbed volume of a suitable probe molecule, a reliable value of the apparent chemisorption stoichiometry [17] can be easily calculated. 
The aim of the present work was to set up and optimise a chemisorption procedure for the determination of Ru dispersion in $\mathrm{Ru} / \mathrm{C}$ catalysts for ammonia synthesis. On the basis of the previous considerations, oxygen has been selected as probe molecule and the experiments were carried out by means of the pulse method. The optimised procedure has been applied, before and after promoters addition, to a set of 2 to $5 \mathrm{wt} \% \mathrm{Ru} / \mathrm{C}$ catalysts, supported on two different carbons. Furthermore, some TEM micrographs helped in evaluating the Ru particle size distribution, for a rough comparison with the results of the oxygen chemisorption analysis.

\section{EXPERIMENTAL}

\subsection{Preparation of Ru black}

Samples of finely dispersed $\mathrm{Ru}$ black were prepared by reduction at $150^{\circ} \mathrm{C}$ in flowing $5 \% \mathrm{H}_{2} / \mathrm{Ar}$ of $\mathrm{Ru}(\mathrm{OH})_{3}$, obtained by dropping a $0.1 \mathrm{M} \mathrm{KOH}$ solution into a $0.02 \mathrm{M}$ aqueous solution of $\mathrm{RuCl}_{3} \cdot \mathrm{xH}_{2} \mathrm{O}$ under vigorous stirring. The precipitate was separated by centrifugation. The solid was then carefully washed and dried in air at $70^{\circ} \mathrm{C}$ for $12 \mathrm{~h}$.

\subsection{Catalyst preparation}

For the development of the oxygen chemisorption method three catalyst samples (V1 to V3, Table 1) have been employed, prepared by impregnation of two different supports with a solution of $\mathrm{K}_{2} \mathrm{RuO}_{4}$, followed by reduction with hydrogen at $320^{\circ} \mathrm{C}$ for $5 \mathrm{~h}$, washing till neutrality of the filtrate and drying at $70^{\circ} \mathrm{C}$ overnight. The supports were a granular, very pure coconut carbon, referred to as $A C$, with $S_{B E T}=1400 \mathrm{~m}^{2} / \mathrm{g}$, and a graphitised carbon, referred to as $\mathrm{G}$, with $\mathrm{S}_{\mathrm{BET}}=170 \mathrm{~m}^{2} / \mathrm{g}$. The corresponding blank samples were prepared through the same procedure, by substituting the $\mathrm{K}_{2} \mathrm{RuO}_{4}$ solution with a $0.5 \mathrm{M}$ solution of $\mathrm{KOH}$. 
The method was then applied to the study of the influence of promoters on $\mathrm{Ru}$ dispersion in ammonia synthesis catalysts. For this purpose three further catalysts (74 to 76, Table 1) were prepared, following the above described procedure, with $\mathrm{Ru}$ loading ranging between 2 and 4 wt \%. Each of them was splitted into two portions: one of them was tested directly and the other (samples $74 \mathrm{P}$ to $76 \mathrm{P}$, Table 1) was promoted. The promoters, $\mathrm{Ba}, \mathrm{Cs}$ and $\mathrm{K}$, were added in the optimal amount found for catalytic purposes, by impregnation from aqueous solution of hydroxides or nitrates [5].

\subsection{Surface area and pulse chemisorption measurements}

The same home-made apparatus was used for pulse chemisorption and surface area measurements. He (SAPIO, purity $\geq 99.9999$ vol \%), Ar (SAPIO, purity $\geq 99.9995$ vol \%), $\mathrm{H}_{2}$ (SIAD, purity $\geq 99.995$ vol \%), $\mathrm{O}_{2}$ (SIAD, purity $\geq 99.999$ vol \%), $\mathrm{N}_{2}(30 \mathrm{vol} \% \mathrm{in} \mathrm{He})$ were fed through independent lines. The gas flow rates were controlled by ST100 Hastings mass flow meters and a six-way valve with sampling loops of different volume was used for pulse injection. Ca. $0.15 \mathrm{~g}$ of catalyst, in $0.15-0.25 \mathrm{~mm}$ particle size, were loaded in a "U" shaped Pyrex tube. This was placed either in an oven or in a dewar flask filled with a cryogenic mixture, depending on the analysis step. The temperature was controlled by an Eurotherm (mod. 818) TRC, through a thermocouple tightly bound to the Pyrex tube. A thermal conductivity detector (TCD) (DANI, mod. HWD 85/4), kept at $150^{\circ} \mathrm{C}$, was used.

The BET surface area of Ru black was measured by the continuous flow technique at $\mathrm{p} / \mathrm{p}_{0}=0.3$ nitrogen relative pressure. The sample was previously reduced in $5 \% \mathrm{H}_{2} / \mathrm{Ar}$ flow at $150^{\circ} \mathrm{C}$ and degassed in Ar flow for $1.5 \mathrm{~h}$ at the same temperature.

The pre-treatment of the supported catalysts, before pulse chemisorption experiments, was performed in the same $\mathrm{H}_{2} / \operatorname{Ar}$ gas mixture at $400^{\circ} \mathrm{C}$ for $1 \mathrm{~h}$, followed by degassing in flowing $\operatorname{Ar}$ at $450^{\circ} \mathrm{C}$. Pulse chemisorption was carried out at various temperatures, between $-81^{\circ} \mathrm{C}$ and $80^{\circ} \mathrm{C}$. Several pulses of $10 \% \mathrm{O}_{2} / \mathrm{He}$ mixture were 
injected at regular intervals, until the area of the recorded peaks became constant. The calibration of the system was done by injecting several series of pulses with loops of various volumes and taking into account the dead volume inside the six-way injection valve. A linear correlation between loop volume and peak area was obtained.

\subsection{TPR measurements}

The TPR apparatus has been described in detail elsewhere [18]. Briefly, ca. $0.15 \mathrm{~g}$ of catalyst in $0.15-0.25 \mathrm{~mm}$ particles were loaded in a Pyrex tube heated by an electric furnace, controlled by an Eurotherm (mod. 822) TRC through a thin thermocouple located within the catalyst bed. The same gases (vide supra) were used. TPR analysis was performed by feeding $40 \mathrm{~cm}^{3} / \mathrm{min}$ of $5 \% \mathrm{H}_{2} / \mathrm{Ar}$ mixture, while heating at $10^{\circ} \mathrm{C} / \mathrm{min}$ up to $400^{\circ} \mathrm{C}$. A refrigerating trap was placed before the detector to freeze out water. The outlet gas flowed through the same TCD described in paragraph 2.3. When needed, a quadrupolar mass spectrometer (mod. PPT Residual Gas Analyser by MKS Instruments) was connected with the TPR system for the detailed analysis of the outlet gas.

\section{RESULTS AND DISCUSSION}

\subsection{TPR analysis}

The TPR diagrams relative to samples V1 and V2 (Fig.1 $a$ and $b$ ), prepared on the as-supplied AC support, showed two reduction peaks. The area of the first peak, around $100^{\circ} \mathrm{C}$, increased with Ru loading ( 0.76 and 5.16 wt $\%$ for $\mathrm{V} 1$ and $\mathrm{V} 2$, respectively) and the peak was absent for the corresponding blanks. Therefore it has been assigned to the reduction of a layer of Ru oxide formed on air exposure of the sample after the reduction of ruthenate. The second peak of sample V2 occurred at lower temperature than the 
corresponding one of sample $\mathrm{V} 1\left(230^{\circ} \mathrm{C}\right.$ against $\left.340^{\circ} \mathrm{C}\right)$ and had lower intensity $(12 \mathrm{mV}$ against $20 \mathrm{mV}$ TCD signal). It was also absent in blank samples.

MS analysis confirmed that the first peak was due to $\mathrm{Ru}$ oxide reduction and allowed to detect $\mathrm{CH}_{4}$ formation, quantitatively corresponding to $\mathrm{H}_{2}$ consumption, connected with the second peak. The sample V3 (Fig.1c), supported on graphitised carbon, showed the first reduction peak only, whose intensity was comparable to that of sample V2 (ca. 5 wt. \% Ru for both catalysts, Table 1). It can be concluded that supported Ru catalyses the breaking of the weakest C-C bonds at the surface of active carbon and that the efficiency of this catalytic action is proportional to the Ru content. In fact, a simple inspection of Fig. $1 b$ shows that in the presence of a high $\mathrm{Ru}$ content the methane formation starts at much lower temperature. This is obviously absent in the graphitised carbon (Fig.1C), as discussed in a previous paper [4]. Moreover, the TPR pattern shows that a final reduction temperature of about $150^{\circ} \mathrm{C}$ in flowing hydrogen is quite sufficient to get metallic Ru in our Ru/C catalysts, but we were forced to choose $400^{\circ} \mathrm{C}$ due to their use for ammonia synthesis.

\subsection{Oxygen chemisorption}

\subsubsection{Experimental data}

A typical example of oxygen chemisorption experiment, carried out by the pulse method, is shown in Fig.2. Practically four pulses fully disappeared (spikes immediately before each peak are obviously not relevant, being due to the switching of the injection valve). The progressive saturation of the sample was monitored till constancy of the peak area. By injecting a further pulse after $30 \mathrm{~min}$ it was observed that the peak area did not change with respect to the previous last pulses, ensuring that, within a reasonable time, no bulk oxidation phenomena took place. The net amount of oxygen adsorbed was determined after subtracting the corresponding blank contribution, which was fairly 
constant (ca. $0.20 \mathrm{Ncm}^{3} / g_{\text {blank}}$ ). The reproducibility of the data was checked by repeating the measures up to 5 times at the same temperature and on different fresh samples of the same batch. The standard deviation was almost 5\%. The chemisorbed oxygen volume per gram of $\mathrm{Ru}$ is reported in Table 1 as $\mathrm{V}_{\mathrm{Ru}}$, expressed as

$$
\left.\mathrm{V}_{\mathrm{Ru}}=\left[\mathrm{V}_{\text {cat }}-(1-x) \mathrm{V}_{\text {blank }}\right)\right] / x
$$

$x$ being the weight fraction of $\mathrm{Ru}$ in the sample and $\mathrm{V}_{\text {cat }}$ the volume of $\mathrm{O}_{2}$ adsorbed per gram of sample.

The determination of the optimal oxygen chemisorption temperature was achieved through experiments carried out at several temperatures, ranging from $-81^{\circ} \mathrm{C}$ to $80^{\circ} \mathrm{C}$. The trend of $\mathrm{V}_{\mathrm{Ru}}\left(\mathrm{Ncm}^{3} / \mathrm{g}_{\mathrm{Ru}}\right)$ went through a minimum-level plateau around $0^{\circ} \mathrm{C}$ (Fig.3). Below $20^{\circ} \mathrm{C}$ the increase of $\mathrm{V}_{\mathrm{Ru}}$ was due to the progressive contribution of physisorption. An increase of $\mathrm{V}_{\mathrm{Ru}}$ was noticed also at $\mathrm{T}>20^{\circ} \mathrm{C}$, probably due to subsurface chemisorption. Our choice was $0^{\circ} \mathrm{C}$, the intermediate temperature of the plateau (see Fig.3).

\subsubsection{Determination of the average chemisorption stoichiometry}

The average chemisorption stoichiometry has been evaluated by determining the amount of oxygen adsorbed by Ru black samples, after measuring their BET surface area by nitrogen physisorption. A TPR experiment showed that our freshly prepared $\mathrm{RuO}_{\mathrm{x}}$, flushed at $150^{\circ} \mathrm{C}$ in $\mathrm{Ar}$ for $0.5 \mathrm{~h}$, was completely reduced to metal at $110^{\circ} \mathrm{C}$.

The determination of BET surface area of $\mathrm{Ru}$ black by nitrogen adsorption/desorption was carried out through the described continuous flow method on freshly reduced samples and the value obtained was $1.1 \pm 0.06 \mathrm{~m}^{2} / \mathrm{g}$ (average value of four measurements). The chemisorption measurements at $0^{\circ} \mathrm{C}$ were carried out immediately after nitrogen adsorption and an oxygen chemisorbed volume $V_{R u}=0.32 \pm 0.05 \mathrm{Ncm}^{3} / g_{R u}$ was obtained (average value of four measurements). An average $\mathrm{Ru} / \mathrm{O}$ chemisorption 
stoichiometry $\mathrm{S}_{\mathrm{av}}\left(\mathrm{Ru^{* }}\right.$ representing the exposed $\mathrm{Ru}$ atoms) of 1.0 was then calculated on the basis of a Ru surface atomic density $\left(\mathrm{C}_{\mathrm{M}}\right)$ of $1.63 \times 10^{19} \mathrm{Ru}$ atoms $/ \mathrm{m}^{2}[19]$.

The dispersion (D) and metal surface area $\left(\mathrm{S}_{\mathrm{Ru}}\right)$ of carbon-supported Ru can be easily calculated from $V_{\mathrm{Ru}}$ on the basis of the following relationships:

$$
\begin{aligned}
& D=2 S_{a v} W_{A} V_{R u} / V_{M} \\
& S_{R u}=2 S_{a v} N_{A} V_{R u} / V_{M} C_{M}
\end{aligned}
$$

$\mathrm{W}_{\mathrm{A}}(\mathrm{g} / \mathrm{mol})$ being the atomic weight of $\mathrm{Ru}, \mathrm{V}_{\mathrm{M}}\left(\mathrm{Ncm}^{3} / \mathrm{mol}\right)$ the molar volume of oxygen and $\mathrm{N}_{\mathrm{A}}\left(\mathrm{mol}^{-1}\right)$ the Avogadro's constant.

By substituting the values of the constants in Eq.2 and 3 one obtains

$$
\begin{aligned}
& D=9.0 \times 10^{-3} \quad V_{R u} \\
& S_{R u}=3.3 V_{R u} \quad\left(\mathrm{~m}^{2} / g_{R u}\right)
\end{aligned}
$$

$V_{R u}$ being expressed as $\mathrm{Ncm}^{3} \mathrm{O}_{2} / \mathrm{g}_{\mathrm{Ru}}$. The results of such a calculation are given in Table 1.

\subsection{TEM image analysis}

While XRD and TEM investigations are now in progress, to check the validity of the above reported $\mathrm{Ru}^{*} / \mathrm{O}$ average chemisorption stoichiometry, we report here a typical TEM image of sample V1 (Fig.4). Apart from a few bigger agglomerates, most of the Ru particles appear to be in the range 10-20. . On the basis of a pseudo-cubic particle shape (a reasonable assumption for so small particles, even for hexagonal-lattice metals), from the $\mathrm{V}_{\mathrm{Ru}}$ value of sample $\mathrm{V} 1$ (Table 1 ) one can calculate an average $\mathrm{Ru}$ particle size $\mathrm{d}_{\mathrm{av}} \cong$ $14 \AA$ A. So these data show a rough agreement between TEM and oxygen chemisorption results, determined according to the present standard procedure. 
In our previous paper [5] the need for reliable chemisorption data was stressed, in order to get information on both influence of promoters and catalyst resistance to deactivation. As discussed in the introduction (vide supra), all the chemisorptive methods proposed so far present some drawback, mostly connected with an arbitrarily assumed chemisorption stoichiometry. The present oxygen chemisorption procedure, which avoids any arbitrary assumption, has been here applied to the characterisation of various $\mathrm{Ru} / \mathrm{C}$ ammonia synthesis catalysts. The following factors have been investigated: i) type of active carbon as support (as supplied or graphitised); ii) $\mathrm{Ru}$ loading; iii) addition of promoters (Ba, Cs, K). The results are collected in Table 1.

For Ru loading of industrial relevance (around $5 \mathrm{wt} \%$ ) the effect of carbon surface area on Ru dispersion showed of relatively low importance. In fact, when carbon surface area decreased by a factor 8 (samples $\mathrm{V} 2$ and $\mathrm{V} 3$, with support $A C$ and $\mathrm{G}$, respectively), Ru dispersion decreased by a factor 2 only. This could be due to the inaccessibility of the micropores of the support for the Ru precursor under the present preparation conditions. Such micropores have been found on AC support only. This explains why carbon graphitisation, which makes the micropores disappear and is of utmost importance in order to achieve a good resistance to methanation $[4,5]$, can be adopted in the manufacture of the catalyst without depressing excessively catalytic activity.

Furthermore, independently of the carbon type used as support, a linear relationship has been found between Ru dispersion and Ru loading (Fig.5, black dots and stars), the former decreasing when increasing the latter. This means that there is a definite advantage, in the industrial practice, in decreasing as much as possible the Ru loading of the catalyst, as the available Ru surface area per unit weight of catalyst does not change appreciably. Indeed, in our previously mentioned paper [5] we showed that very good catalysts can be prepared with a Ru loading as low as ca. $5 \mathrm{wt} \%$. Of course, however, when the metal loading becomes too low, problems may arise as for catalyst life. 
At last, it has been found, rather surprisingly, that the addition of promoters has virtually no effect on Ru dispersion (Fig.5, open dots), though such an addition was done after loading of the $\mathrm{Ru}$ precursor, followed by reduction to metallic $\mathrm{Ru}$, and in spite of a very high loading of promoters. Indeed, the total atomic percentage of the three promoters was about 5 times that of Ru and no oxygen chemisorption was detected on the promoters supported in the absence of Ru. Something similar was found by Kowalczyk and coworkers [8] with Ba-promoted $\mathrm{Ru} / \mathrm{C}$ catalysts. Then it can be concluded that, in spite of their large amount, the three promoters do not prevent the access of the gas phase to $\mathrm{Ru}$ particles. This explains the exceptional efficiency of $\mathrm{Ba}-\mathrm{Cs}-\mathrm{K}$ promotion in the present catalysts $[4,5]$.

\section{CONCLUSIONS}

A procedure for determining Ru dispersion and Ru surface area of the ready-to-use, promoted $\mathrm{Ru} / \mathrm{C}$ catalyst for ammonia synthesis has been set up and optimised. Such a procedure, based on experimentally determined $R u^{*} / O$ average chemisorption stoichiometry, was applied to a set of either promoted or unpromoted catalyst samples, with different carbon supports and various Ru loadings, and showed reliable and versatile, allowing to determine the effect of Ru loading, of the nature of support and of the addition of promoters on Ru dispersion and surface area.

The main factor influencing $\mathrm{Ru}$ dispersion proved to be $\mathrm{Ru}$ loading, with a linear inverse relationship, while the addition of even large amounts of Ba-Cs-K promoters has practically no influence. These results can be helpful in elucidating several aspects of the behaviour of $\mathrm{Ru} / \mathrm{C}$ as catalyst for ammonia synthesis.

\section{ACKNOWLEDGEMENTS}


The valuable help of V.Quarti and T.Cocchi in collecting chemisorption data and of the late Professor G.Fagherazzi for providing the TEM micrographs is gratefully acknowledged.

\section{REFERENCES}

1. U. S. Pat. 4,163,775, Aug. 7 (1979), to British Petroleum Co.

2. U. S. Pat. 4,568,532, Feb. 4 (1986), to Kellogg, M. W., Co.

3. Z. Kowalczyk, J. Sentek, S. Jodzis, E. Mizera, J. Goralski, T. Paryjczak, R. Diduszko, Catal. Lett., 45 (1997) 65.

4. L. Forni, D. Molinari, I. Rossetti and N. Pernicone, Appl. Catal. A: General, 185 (1999) 269.

5. I. Rossetti, N. Pernicone, L. Forni, Appl. Catal. A: General, 208 (2001) 271.

6. S.R. Tennison, in Catalytic Ammonia Synthesis, J. R. Jennings, Ed., Plenum Press, New York (1991), p. 303.

7. W. Raròg, Z. Kowalczyk, J. Sentek, D. Skladanowski, J. Zielinski, Catal. Lett., 68 (2000) 163.

8. Z. Kowalczyk, S. Jodzis, W. Rarog, J. Zielinski, J. Pielaszek, A. Presz, Appl. Catal. A: General, 184 (1999) 95.

9. K. Lu, B. J. Tatarchuk, J. Catal., 106 (1987) 166.

10. D.O. Uner, M. Pruski, T. S. King, J. Catal., 156 (1995) 60.

11.J.T. Yates, Jr., C.H.F. Peden, J.E. Honstand, D.W. Goodman, Surf. Sci., 160 (1985) 37.

12. M. Kantcheva, S. Sayan, Catal. Lett., 60 (1999) 27.

13. N.E. Buyanova, A.P. Karnaukhov, N.G. Koroleva, I.D. Ratner, O.N. Chernyavskaya, Kinet. I Katal., 13 (1972) 1533.

14. G. Blanchard, H. Charcosset, React. Kinet. Catal. Lett, 15 (1980) 209.

15. S. Khaja Masthan, K.V.R. Chary, P. Kanta Rao, J. Catal., 124 (1990) 289. 
16. H. Berndt, U. Müller, Appl. Catal. A: General, 180 (1999) 63.

17. G. Fagherazzi, P. Canton, P. Riello, N. Pernicone, F. Pinna, M. Battagliarin, Langmuir, 16 (2000), 4539.

18. L. Forni, M. Toscano and P. Pollesel, J. Catal., 130 (1991) 392.

19.J.R. Anderson, K.C. Pratt, Introduction to Characterization and Testing of Catalysts, Academic Press, New York, 1985, p.7. 
Table 1: Oxygen chemisorption data at $0^{\circ} \mathrm{C}$

\begin{tabular}{|c|c|c|c|c|c|c|}
\hline Cat & $\begin{array}{c}\mathbf{R u}(\mathrm{wt} \\
\%)^{\mathrm{a}}\end{array}$ & Support $^{b}$ & $\begin{array}{c}\mathbf{V}_{\text {cat }} \\
\left(\mathrm{Ncm}^{3} / \mathrm{g}_{\text {cat }}\right)\end{array}$ & $\begin{array}{c}\mathbf{V}_{\mathbf{R u}} \\
\left(\mathrm{Ncm}^{3} / \mathrm{g}_{\mathrm{Ru}}\right)\end{array}$ & $D=R u^{*} / R u$ & $\begin{array}{c}\mathbf{S}_{\mathrm{Ru}} \\
\left(\mathrm{m}^{2} / \mathrm{gRu}_{\mathrm{Ru}}\right)\end{array}$ \\
\hline V1 & 0.76 & $A C$ & 0.89 & 87.4 & 0.79 & 288 \\
\hline V2 & 5.16 & $A C$ & 0.83 & 12.5 & 0.11 & 41 \\
\hline V3 & 4.94 & $\mathrm{G}$ & 0.52 & 6.6 & 0.06 & 22 \\
\hline 74 & 2.30 & $\mathrm{G}$ & 1.23 & 44.9 & 0.40 & 148 \\
\hline 75 & 3.39 & G & 1.24 & 30.8 & 0.28 & 102 \\
\hline 76 & 4.25 & $\mathrm{G}$ & 1.01 & 19.3 & 0.17 & 64 \\
\hline $74 \mathrm{P}^{\mathrm{c}}$ & 2.13 & $G$ & 1.39 & 51.9 & 0.47 & 171 \\
\hline $75 \mathrm{P}^{\mathrm{c}}$ & 3.03 & $G$ & 1.19 & 29.1 & 0.26 & 96 \\
\hline $76 \mathrm{P}^{\mathrm{c}}$ & 3.10 & $\mathrm{G}$ & 1.26 & 25.0 & 0.23 & 83 \\
\hline
\end{tabular}

a) Value referred to the final catalyst weight.

b) $A C=$ granular active carbon, $S_{B E T}=1400 \mathrm{~m}^{2} / \mathrm{g} ; \mathrm{G}=$ graphitised carbon, $S_{B E T}=170 \mathrm{~m}^{2} / \mathrm{g}$

c) Atomic ratios: $\mathrm{Ba} / \mathrm{Ru}=0.6, \mathrm{Cs} / \mathrm{Ru}=1.0, \mathrm{~K} / \mathrm{Ru}=3.5$.

\section{FIGURE CAPTIONS}

Fig. 1: TPR pattern of samples V1 (a), V2 (b) and V3 (c).

Fig. 2: Typical pulse chemisorption diagram, relative to sample V1.

Fig. 3: $\mathrm{O}_{2}$ chemisorption data vs. temperature (sample V3, Table 1).

Fig. 4: Example of TEM micrograph of sample V1.

Fig. 5: Ru dispersion vs. loading for samples: on G support: (•) without promoters, (口) with promoters; on AC support, without promoters (*). 
Fig. 1a

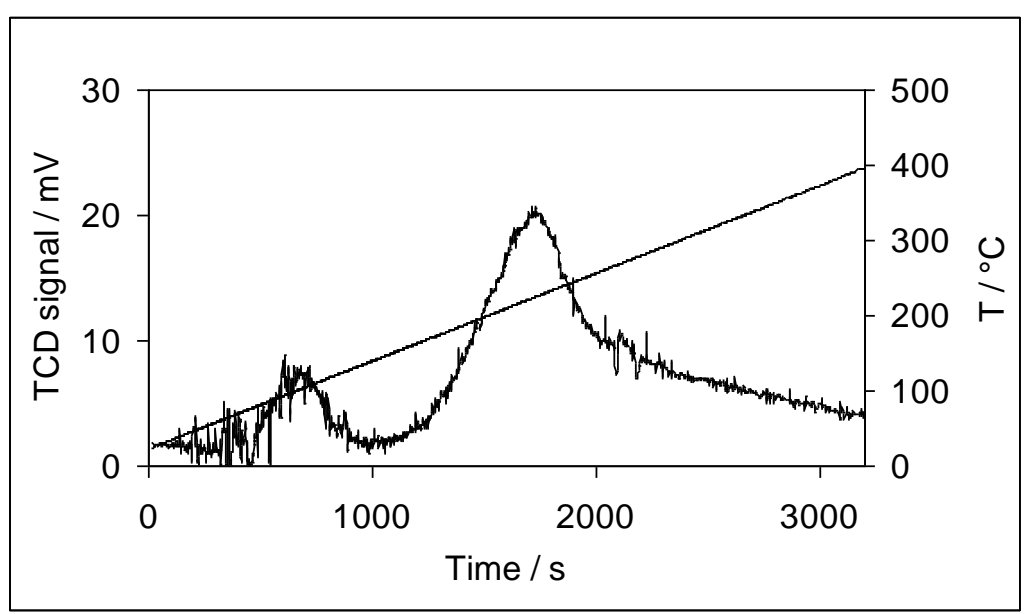

Fig. 1b

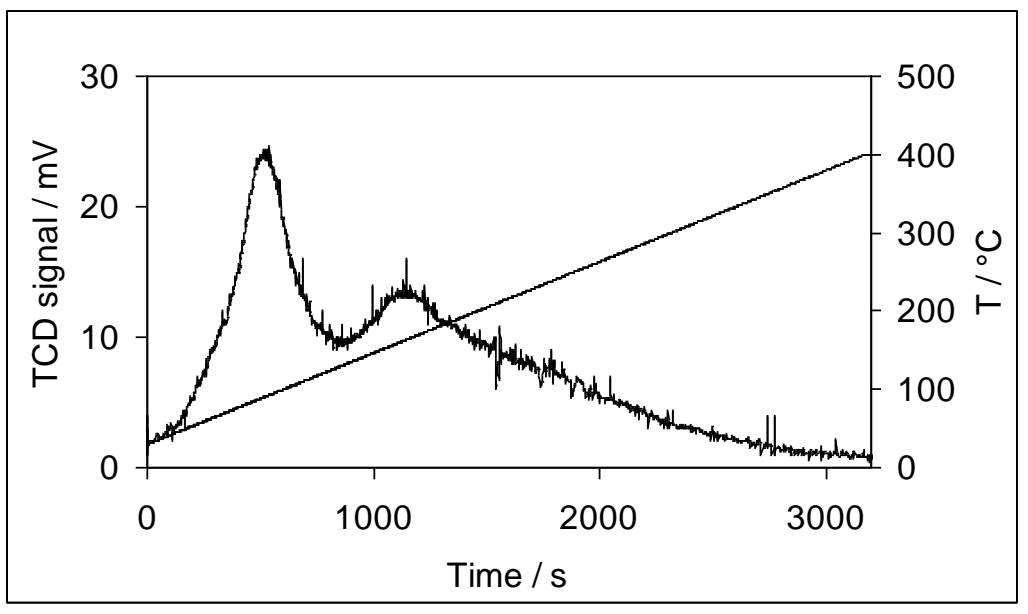

Fig. 1c

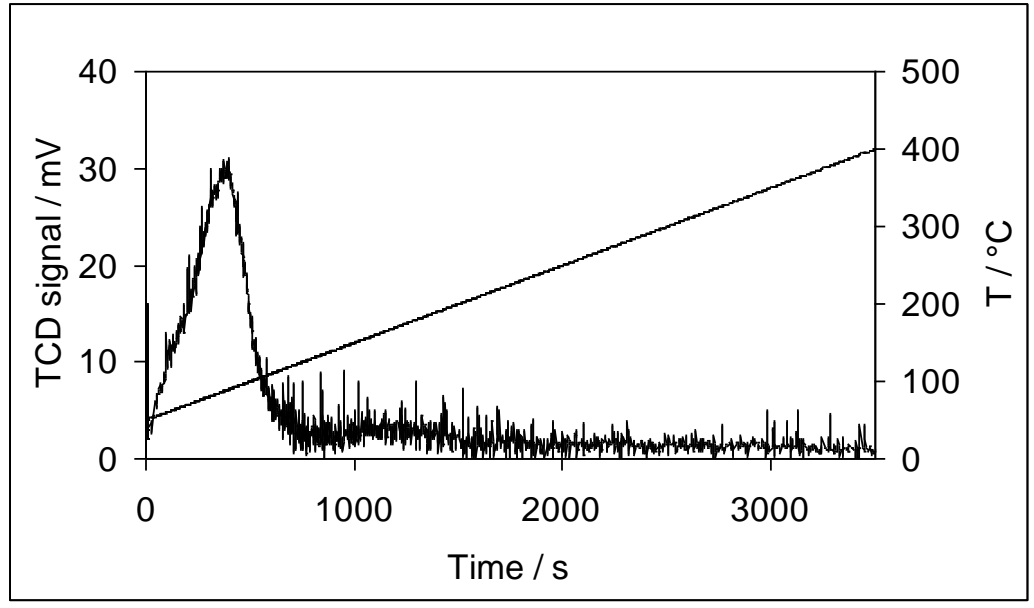


Fig. 2

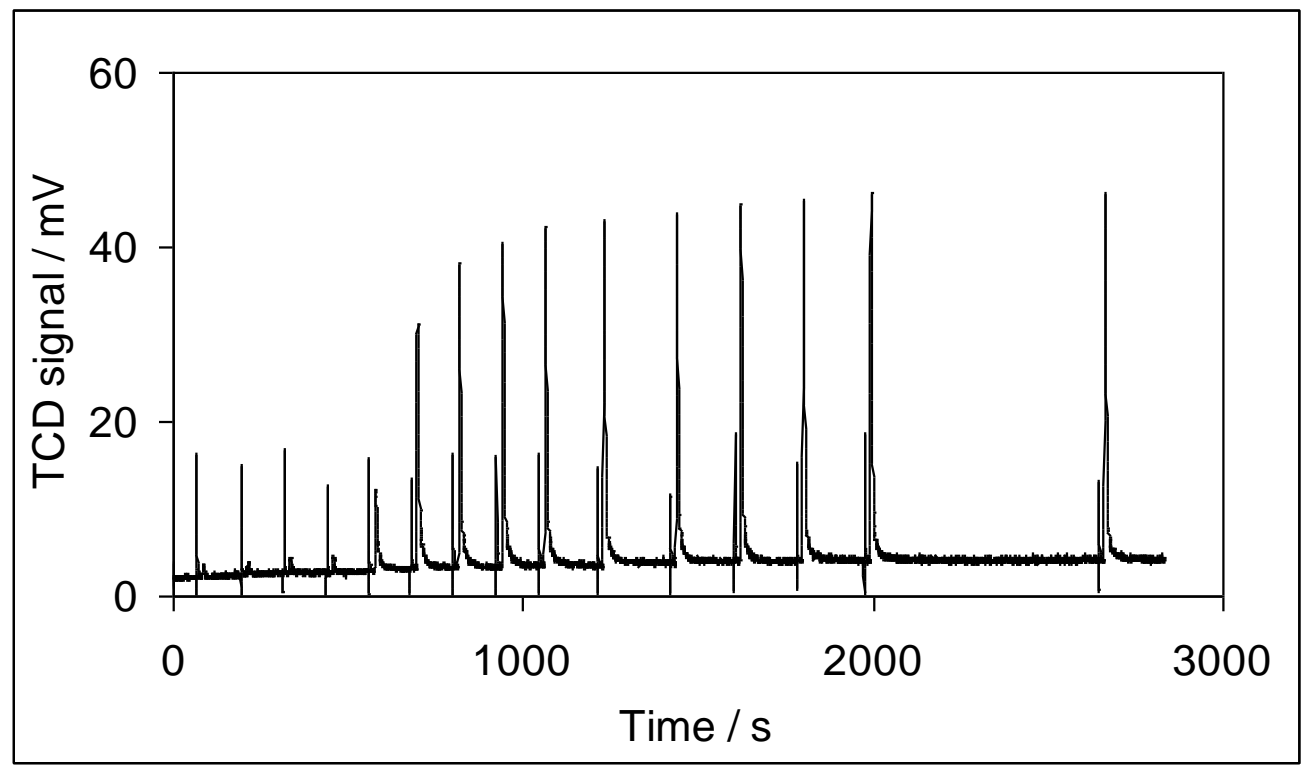

Fig. 3

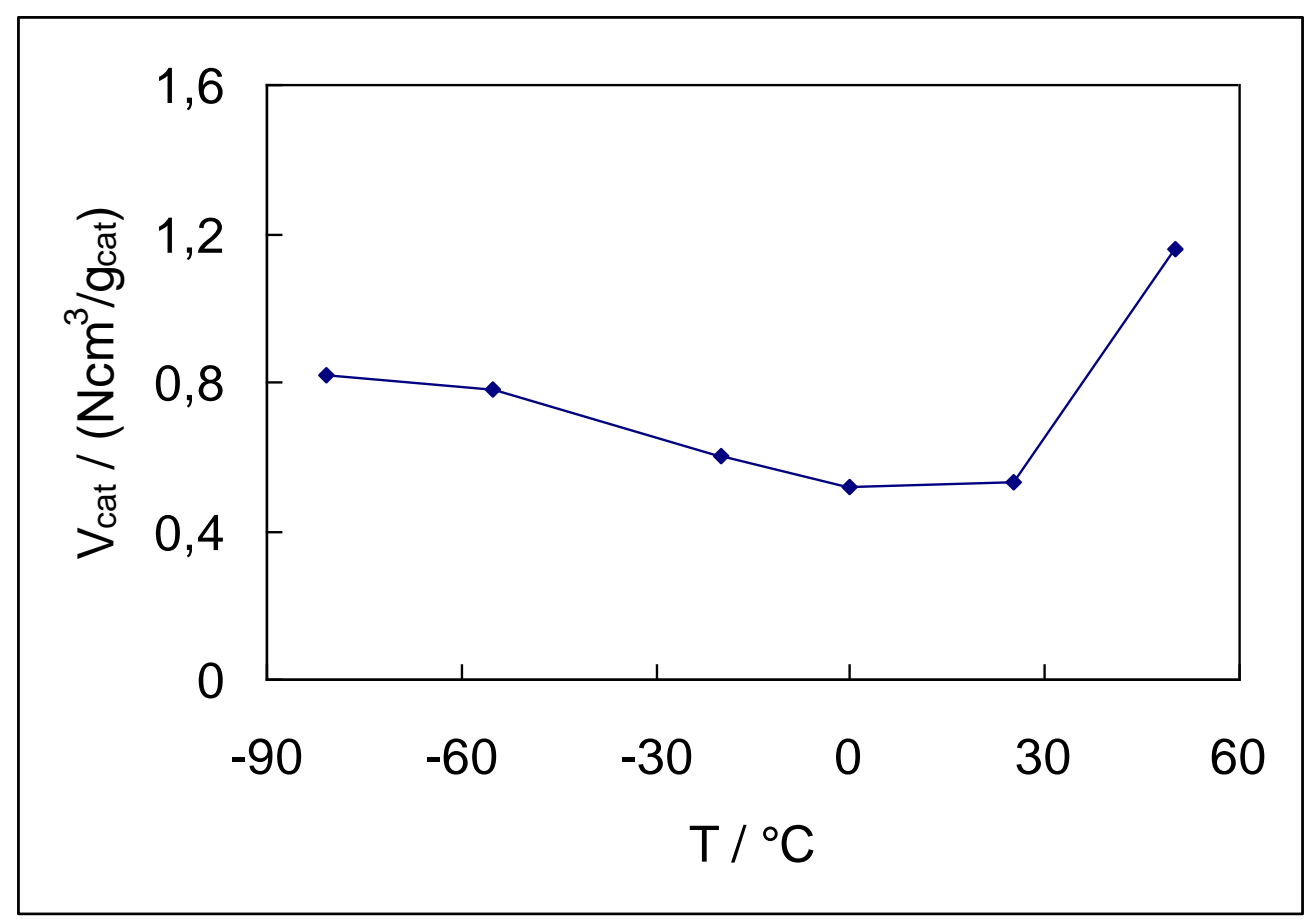


Fig. 4

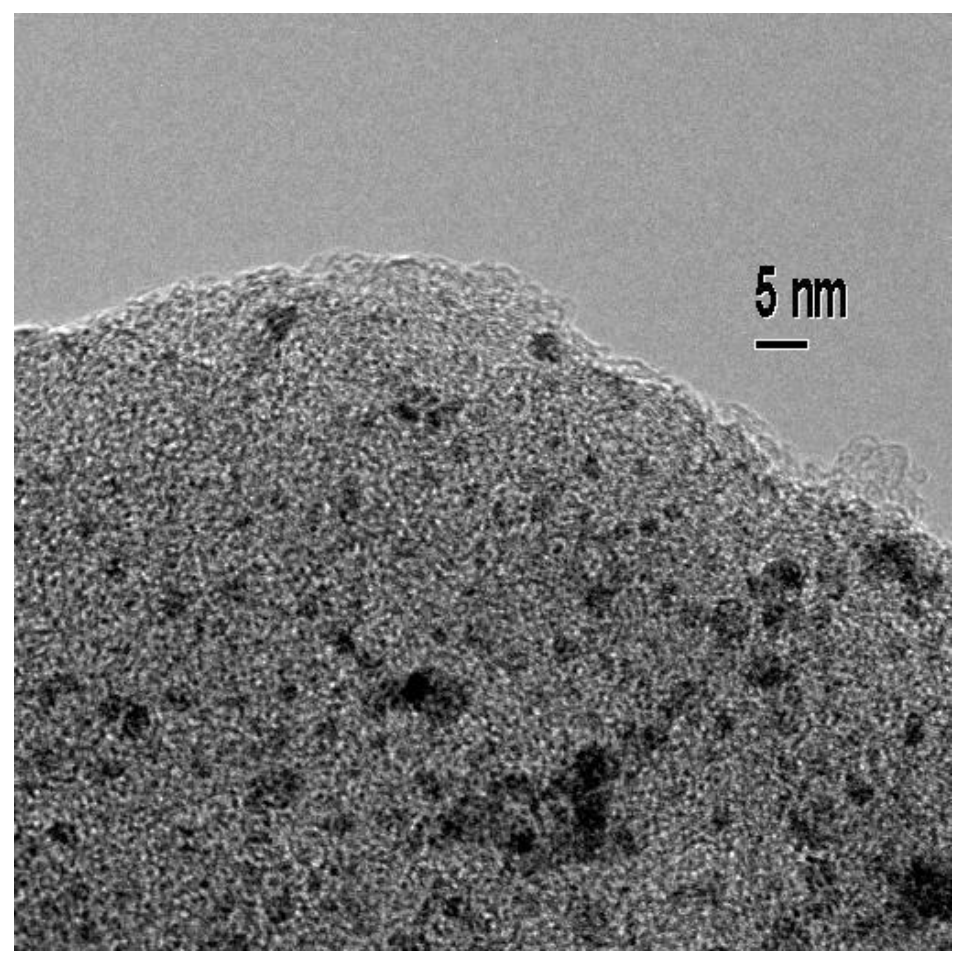

Fig. 5

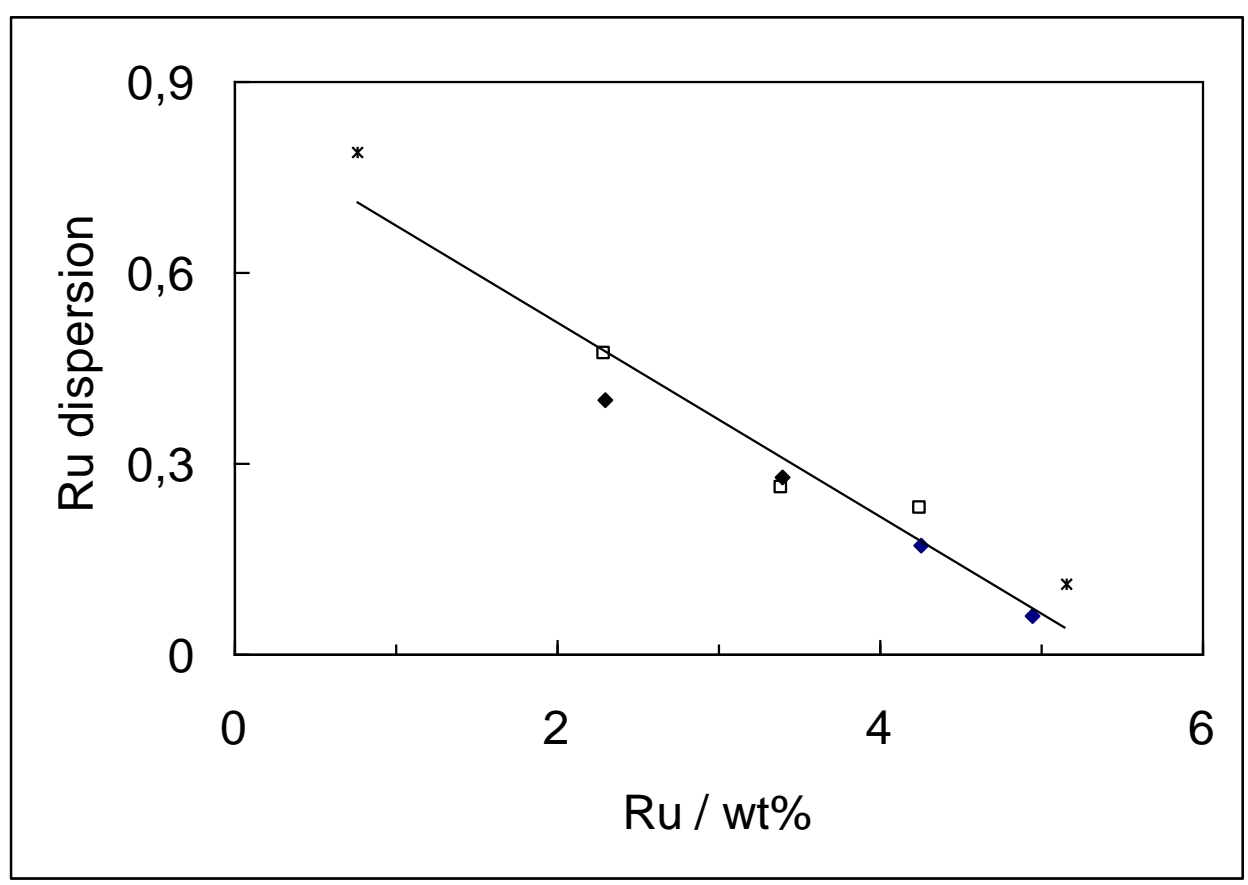

